\title{
Biomedical Electronics Curriculum Reform in the Concept of CDIO Education Countermeasures
}

\author{
Yutong Zha, Boyu Si, Xiaoou Li, Jiayong Yan* \\ School of Medical Instrument \\ Shanghai University of Medicine \& Health Sciences \\ Shanghai, China \\ zhayt@sumhs.edu.cn
}

\begin{abstract}
Biomedical electronics is a compulsory course for biomedical engineering undergraduates which contains theory courses and experiment courses. It uses knowledge of electronics to solve life science problems. To improve the effectiveness of learning, CDIO Education Countermeasures is introduced in Biomedical Electronics Curriculum reform. The theory course content divided into chapters in modules of medical devices. After the theoretical lessons, based on what they have learned, each of the students writes a research report about any kind of wearable devices of physiological signal detection. Combining with theoretical knowledge and reports, student's concept design a wearable device and implement its hardware and software in groups during experiment courses. The experimental results show that CDIO makes students become the host of learning. The combination of the knowledge target, skill target and attitude target effectively improves students' knowledge, ability and quality. Learning situation questionnaire results show that $\mathbf{8 1 \%}$ of students think that writing research report is helpful to learn this course.
\end{abstract}

Keywords-biomedical engineering; biomedical electronics; CDIO; research report; integration of theory and practice

\section{INTRODUCTION}

Biomedical engineering is a new branch of science. It integrates theory and methods of engineering, physics, biology and medicine, develops researches of various changes in human body system, and control this kind of change by means of engineering technology. Its purpose is to solve the problems in medical, safeguard human health, provide service for the prevention of disease, diagnosis, treatment and rehabilitation.

Biomedical electronics is a compulsory course offered in the junior year for undergraduates. Its theory courses contain 32 class hours, and experiment courses contains 32 class hours. Biomedical electronics deepens the basic knowledge of electronics, at the same time, combines biomedicine and engineering closely and organically. Also, students need to build cognition of medical instrument system and gain engineering skills through the corresponding practice experiment course.

The CDIO education countermeasures are one of the latest

This work was supported by the curriculum construction program of Cooperative Education Program of Ministry of Education (201802016045) Shanghai University of Medicine \& Health Sciences - "Undergraduate Innovation Ability Training Based on wearable scientific research platform Four-One Project” and "A new system for measuring cerebral hemodynamics" 2019 achievements of international engineering education reform in recent years. CDIO is for conceive (C), design (D) ,implement (I) and operate $(\mathrm{O})$. It takes the life cycle from product research and development to product operation as the carrier. Students learn engineering in an active, practical way and the courses are organically linked. Students should have basic knowledge of engineering, personal ability, interpersonal and team skills, and engineering system ability.

Biomedical electronics emphasizes that all the knowledge in this course is based on engineering, and all about products and systems built in the real world, which is exactly consistent with the vision of CDIO. For this reason, the CDIO education countermeasures are introduced in biomedical electronics curriculum design.

According to CDIO syllabus and standard documents provided by CDIO official website[1-2], the CDIO Syllabus classified learning outcomes into four high-level categories: technical knowledge, personal and professional attributes, interpersonal skills, and the skills specific to the engineering profession[3-5]. In order to match the skill requirements, some reform measures are applied to biomedical electronics. For all the students who learned this course, process evaluation and result evaluation are objective evaluation indexes, learning situation questionnaire is a subjective evaluation index. All these indexes are used to evaluate the effect of the reform.

\section{BIOMEDICAL ELECTRONICS CURRICULUM REFORM}

The course objectives of biomedical electronics includes understanding the process of biomedical electronics development, mastering the main classification, technical characteristics, design ideas, designing principles and steps of common medical electronic instruments, understanding the relationship between unit circuit analysis and overall circuit design correctly, and understanding the key technology and development direction of biomedical electronics. Although the existing curriculum also includes theoretical and experimental teaching, most of the experiments correspond to the chapters of the theory course, rather than integrate the system organically. This leads to fragmentation of knowledge which is not applicable to engineering applications. Therefore, taking the integration quality training as the goal, The CDIO education countermeasures is implanted into biomedical electronics curriculum reform. The following are specific implementation methods [6]. 


\section{A. Conceivement and Design}

Restricted to theoretical class hour arrangement, the textbook chapters have been rearranged into eleven modules. These modules contain the most simple medical devices involving routine functions. The chapters of this course, knowledge points and the assignment of class hours are shown in TABLE I. The first module is a brief cognization of biomedical electronics. From the second to the nine modules are the regular units of the system. The last three modules help students to understand medical devices from the composite structure level.

TABLE I. ELEVEN LEARNING MODULES OF BIOMEDICAL ELECTRONICS

\begin{tabular}{|c|l|c|}
\hline Module & \multicolumn{1}{|c|}{ Content } & $\begin{array}{c}\text { Class } \\
\text { hour }\end{array}$ \\
\hline 1 & Introduction & 2 \\
\hline 2 & Sensor and Interface Circuits & 2 \\
\hline 3 & Signal-amplifier & 4 \\
\hline 4 & Signal-filter & 4 \\
\hline 5 & Signal operation & 4 \\
\hline 6 & $\begin{array}{l}\text { Linear Transformation and Nonlinear } \\
\text { Transformation }\end{array}$ & 4 \\
\hline 7 & A/D and D/A & 2 \\
\hline 8 & Signal Remote Transmission & 2 \\
\hline 9 & Biomedical Signal Detection System & 2 \\
\hline 10 & EEG & 2 \\
\hline 11 & Pulse Oximeter & 4 \\
\hline
\end{tabular}

Even though the content covers many commen modules in regular wearable devices in medical area, knowledge points are too decentralized to form system consciousness for student. According to what they have learned in the first nine modules, students are asked to write reports about any kind of medical electronic device. The research report has a uniform template, it includes five sections.

- The Cover. This section has a uniform template, including the school badge, main title 'Undergraduate research report', subtitle 'Study on XX Detection Method Based on XX technology', information of the writer such as student ID and name, finally, the finishing time of this report.

- Research Progress and Development. This section mainly introduces the main implementation methods of the selected technology and the research progress at home and abroad.

- Research on XX Detection Method Based on XX technology. This section introduces the principle of the selected technology and its design scheme in XX detection, including the design of system structure.

- Selection of Devices' Model and Type. The device selection and basis of the detection system are introduced in detail in this section.

- The Summary and Prospect. This section mainly introduces the development prospect and trend of the selected technology in XX detection.

In the theory course period, EEG and pulse oximeter are introduced as two examples of common medical electronic instruments. Furthermore, some device manuals are uploaded to cloud storage which is convenient for students to study and reference. All the students not only can learn how to carry out a research and produce a report, but also give a try to design a system by their own after theoretical courses.

\section{B. Implement and Operation}

For engineering students, practice is a very important part of school learning. Though biomedical engineering is a interdiscipline, Practice is still an indispensable part in the construction of knowledge system. Curricular experiments in biomedical electronics require top-down design of the system. Firstly, students select a topic in one of three directions in TABLE II.

TABLE II. DIRECTION AND SENSOR

\begin{tabular}{|c|l|c|}
\hline No. & \multicolumn{1}{|c|}{ Direction } & Sensor \\
\hline 1 & ECG Measurement & Electro cardio-electrode \\
\hline 2 & $\mathrm{SO}_{2}$ Detection & Photoelectric Sensor \\
\hline 3 & Pulse Rate (PR) Monitoring & Piezoelectric Sensors \\
\hline
\end{tabular}

Even though Electroencephalo-graph (ECG), Oxyhemoglobin saturation $\left(\mathrm{SO}_{2}\right)$ and Pulse Rate (PR) monitoring using different sensors, they have one common that all of them provide heart rate (HR) or pulse rate (PR) which is the most commonly used physiological parameter. Beyond that, PR and HR are easily tested with other standard instruments. The specific implementation process is as follows.

- Choose a direction in TABLE II. Each of student chooses a direction in above-mentioned three topics; try to be consistent with the research report.

- Divide into groups. Those who choose the same direction are grouped together, working in groups of three. Grade is given in group, and every student in one group has same grade.

- Simulation Experiment. After group discussion, the hardware design of the system is simulated on the computer. We choose 'Multisim' as the simulation software. After adjusting the design until feasible, devices model and parameters are determined and fixed,

- Apply Devices and Welding Circuit. An Arduino microchip and the intelligent peripheral interface form the hardware of the system, which assures the realtime accurate data acquisition and system control. Other integrated devices are controlled by Arduino.

- Debugging. CommAssistant is used for monitoring raw data. This allows students to interactively debug your hardware and software.

- Data Collection. Original data is detected by system and stored in computer after wireless transmission by Bluetooth.

- Write Algorithm Program. An algorithm program should be written to calculate HR or PR by MATLAB no matter what kind of technique that be used. 


\section{Organization and Security}

For theoretical courses, all courses are completed in the classroom. All the courseware is uploaded to an app called Lanmo Cloud Class.

As for the research report writing, all the work is completed after class. However, instructors need to provide relevant document information such as literatures, the device manuals, application example cases and proper guidance.

The experimental curriculum is conducted in the laboratory. Because of the compulsory course, all students have to participate in the practice. In order to cultivate students' sense of teamwork, which are the interpersonal skills as CDIO emphasized. Grouping is not free combination, but group by choice. Everyone can be more involved in the implementation process.

\section{Checkup and Assessment}

In order to match the skill requirements, some method are applied to assess the effect of biomedical electronics curriculum reform. For all the students who learned this course, process evaluation and result evaluation are objective evaluation indexes, learning situation questionnaire is a subjective evaluation index. All these indexes are used to evaluate the effect of the reform.

TABLE III. QUESTIONS AND OPTIONS

\begin{tabular}{|c|c|c|}
\hline & Question & Options \\
\hline 1 & How well have you understood the knowledge provided in this course? & $\begin{array}{ll}\text { A. } & \text { Fully understanding } \\
\text { B. } & \text { Most understanding } \\
\text { C. } & \text { Basic understanding } \\
\text { D. } & \text { Not understanding } \\
\end{array}$ \\
\hline 2 & How well do you understand the objects and characteristics of biomedical signals? & $\begin{array}{ll}\text { A. } & \text { Fully understanding } \\
\text { B. } & \text { Most understanding } \\
\text { C. } & \text { Basic understanding } \\
\text { D. } & \text { Not understanding }\end{array}$ \\
\hline 3 & How well do you understand the biomedical signal measurement and processing module? & $\begin{array}{ll}\text { A. } & \text { Fully understanding } \\
\text { B. } & \text { Most understanding } \\
\text { C. } & \text { Basic understanding } \\
\text { D. } & \text { Not understanding } \\
\end{array}$ \\
\hline 4 & $\begin{array}{l}\text { How well do you understand the principles, design ideas and application knowledge of medical diagnostic } \\
\text { instruments? }\end{array}$ & $\begin{array}{ll}\text { A. } & \text { Fully understanding } \\
\text { B. } & \text { Most understanding } \\
\text { C. } & \text { Basic understanding } \\
\text { D. } & \text { Not understanding }\end{array}$ \\
\hline 5 & How well do you understand the functional modules and electronic circuits of ECG equipment? & $\begin{array}{ll}\text { A. } & \text { Fully understanding } \\
\text { B. } & \text { Most understanding } \\
\text { C. } & \text { Basic understanding } \\
\text { D. } & \text { Not understanding } \\
\end{array}$ \\
\hline 6 & How well do you understand the functional modules and electronic circuits of Pulse Oximeter equipment? & $\begin{array}{ll}\text { A. } & \text { Fully understanding } \\
\text { B. } & \text { Most understanding } \\
\text { C. } & \text { Basic understanding } \\
\text { D. } & \text { Not understanding }\end{array}$ \\
\hline 7 & Do you think writing research reports will help the course to some extent? & $\begin{array}{l}\text { A. Very helpful } \\
\text { B. A little help } \\
\text { C. No big help } \\
\text { D. Totally unnecessary }\end{array}$ \\
\hline 8 & What is most helpful to the course by writing a research report? & $\begin{array}{l}\text { A. Understand cutting-edge technology } \\
\text { B. Establish structural design ideas } \\
\text { C. Know how to choose a device } \\
\text { D. }\end{array}$ \\
\hline
\end{tabular}

The questionnaire consists of 20 questions, including 19 objective questions and 1 subjective question. Eight of them are related to the curriculum reform. These questions are shown in TABLE III.

\section{E. Resources and Environment}

Experimental equipments are provided by the teacher. Experimental devices are applied by students, approved and distributed by teachers. All the students should observe laboratory safety rules during the experiment. Any violation of laboratory regulations will result in the cancellation of course grade.

\section{EVALUATION OF CURRICULUM REFORM}

There are two classes that take biomedical electronics courses in this academic year. One class has 84 students, and this class is reformed in the concept of CDIO education countermeasures. Another has 42 students without any reform.

\section{A. Teaching effectiveness of Theory Course}

Comparing the final exam scores of the compulsory course between two classes, the score section statistical distribution are listed in the following TABLE IV. It can be found from the table that the passing rate of Class One is nearly 2 percent higher than that of Class Two. The number of students in Class One was nearly five percent higher than that in Class Two. Most of the people in Class One are evenly distributed in 60-69, 70-79 and 80-89 Scaled Score. However, most of the people 
are evenly distributed in 60-69, 70-79 and Scaled Score in the Class Two, there are fewer students got higher score.

TABLE IV. SCORE SECTION STATISTICAL Distribution

\begin{tabular}{|c|c|c|c|c|c|c|}
\hline \multirow{2}{*}{$\begin{array}{c}\text { Scaled } \\
\text { Score }\end{array}$} & \multicolumn{3}{|c|}{ Class One } & \multicolumn{3}{c|}{ Class Two } \\
\cline { 2 - 7 } Counting & $\boldsymbol{p}(\%)$ & $\boldsymbol{\Sigma} \boldsymbol{p}(\%)$ & Counting & $\boldsymbol{p}(\%)$ & $\boldsymbol{\Sigma} \boldsymbol{p}(\%)$ \\
\hline $0-49$ & 4 & 4.76 & 4.76 & 3 & 7.14 & 7.14 \\
\hline $50-59$ & 8 & 9.53 & 14.29 & 4 & 9.52 & 16.67 \\
\hline $60-69$ & 21 & 25.00 & 39.29 & 15 & 35.72 & 52.38 \\
\hline $70-79$ & 28 & 33.33 & 72.62 & 16 & 38.10 & 90.48 \\
\hline $80-89$ & 17 & 20.24 & 92.86 & 3 & 7.14 & 97.62 \\
\hline $90-100$ & 6 & 7.14 & 100.00 & 1 & 2.38 & 100.00 \\
\hline
\end{tabular}

The proportion polygon of scaled score for two classes is shown in Fig.1. Through observation, it can be found that the distribution of scores in class one is closer to the normal distribution. It indicates that the average learning effect of the class is in line with expectations.

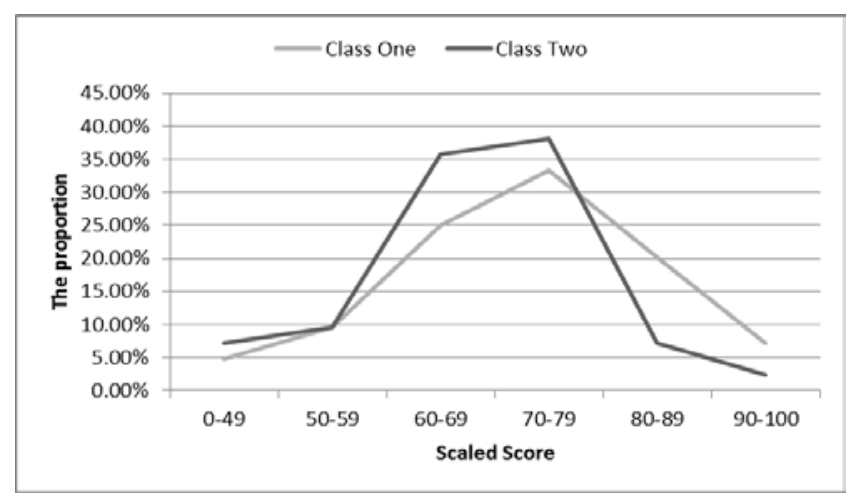

Fig. 1. The Proportion Polygon of Scaled Score for Two Classes

In addition, the average score of Class One was 76.08 and that of Class Two was 71.75. Class one has a higher average than class two.

\section{B. Teaching effectiveness of Experimental Course}

In the early stage, students consulted a lot of materials during the writing of research reports Students have a preliminary impression of the engineering design of the experimental content. In the research report, students summarized the modules needed for system implementation and the devices needed for module function implementation, especially integrated devices For the development and implementation of complex systems, the theoretical level has been designed. So, the students in Class One are more prepared than those in Class Two.

In the course of the experiment, students from one class were grouped in directions and completed the system design in groups. The preliminary investigation and preparation of each person in the group are consistent with the experimental content, which greatly improves the implementation efficiency. Small groups are more conducive to developing perseverance, a sense of urgency and determination to accomplish tasks, and flexible wisdom. Students are able to use their surroundings and collective resources more cleverly, collaborate and discuss ideas. It is easier to stimulate students' creative thinking.
The experiment completion of class one and class two was evaluated, the experiment completion degree and speed of the First Class is much higher than that of the Second Class. In addition, during the implementation of the project, students closely combine the research content with the experimental content, which stimulates their cognitive ability and knowledge integration ability.

\section{Learning Situation Questionnaire Results}

Through the analysis of the results of the questionnaire, it can be found that the students' scores of knowledge goals basically reach about $85 \%$. Only one student, accounting for 1.19 percent of the results, thought the method was unnecessary in the form of independent learning. Most students think the research report is effective for understanding cuttingedge technology and establishing structural design ideas, which consistent with the original intention of this reform design.

TABLE V. QUESTIONNAIRE STATISTICAL DisTRIBUTION

\begin{tabular}{|c|c|c|c|}
\hline No. & Options & Counting & Proportion (\%) \\
\hline \multirow{4}{*}{1} & $\mathrm{~A}$ & 9 & 10.71 \\
\hline & B & 26 & 30.95 \\
\hline & $\mathrm{C}$ & 36 & 42.86 \\
\hline & $\mathrm{D}$ & 13 & 15.48 \\
\hline \multirow{4}{*}{2} & A & 9 & 10.71 \\
\hline & B & 34 & 40.48 \\
\hline & $\mathrm{C}$ & 32 & 38.10 \\
\hline & $\mathrm{D}$ & 9 & 10.71 \\
\hline \multirow{4}{*}{3} & A & 10 & 11.90 \\
\hline & B & 24 & 28.57 \\
\hline & $\mathrm{C}$ & 36 & 42.86 \\
\hline & $\mathrm{D}$ & 14 & 16.67 \\
\hline \multirow{4}{*}{4} & A & 12 & 15.48 \\
\hline & B & 22 & 26.19 \\
\hline & $\mathrm{C}$ & 34 & 40.48 \\
\hline & D & 16 & 19.05 \\
\hline \multirow{4}{*}{5} & A & 13 & 15.48 \\
\hline & B & 26 & 30.95 \\
\hline & $\mathrm{C}$ & 35 & 41.67 \\
\hline & $\mathrm{D}$ & 10 & 11.90 \\
\hline \multirow{4}{*}{6} & A & 9 & 10.71 \\
\hline & B & 24 & 28.57 \\
\hline & $\mathrm{C}$ & 35 & 41.67 \\
\hline & $\mathrm{D}$ & 16 & 19.05 \\
\hline \multirow{4}{*}{7} & A & 19 & 22.61 \\
\hline & B & 49 & 58.34 \\
\hline & $\mathrm{C}$ & 15 & 17.86 \\
\hline & $\mathrm{D}$ & 1 & 1.19 \\
\hline \multirow{4}{*}{8} & A & 27 & 32.14 \\
\hline & B & 29 & 34.52 \\
\hline & $\mathrm{C}$ & 12 & 14.29 \\
\hline & $\mathrm{D}$ & 16 & 19.05 \\
\hline
\end{tabular}

\section{SUMMARY}

In order to improve the effectiveness of learning, the integration of theory and practice with the CDIO model as the core of the embedded system curriculum system is built in the Biomedical Engineering. The CDIO project teaching can strengthen the basic knowledge of engineering; cultivate students' comprehensive application ability. In addition, through the construction of the experimental platform of embedded system teaching and scientific research, the personal ability, interpersonal and team skills is improved. The training 
quality of engineering system ability in medical universities has been promoted.

\section{REFERENCES}

[1] Crawley E F, Malmqvist J, Östlund S, et al. "The CDIO Syllabus: Learning Outcomes for Engineering Education”, Rethinking Engineering Education, 2014.

[2] Minin M, Kriushova A, Muratova E. "Assessment of the CDIO syllabus learning outcomes: From theory to practice”, International Conference on Interactive Collaborative Learning. 2015.

[3] Haupt, G., Webber-Youngman, R.C.W. Engineering education. "An Integrated Problem-solving Framework for Discipline specific
Professional Development in Mining Engineering”. Journal of the Southern African Institute of Mining and Metallurgy, 2018, 118, 27-37.

[4] Kabukcuoglu, S. Calretinin. "Expression in Endometriosis. Is calretinin positive tubal epithelium origin of fallopian tube carcinoma”. European Journal of Gynaecological Oncology, 2017, 38, 905-909.

[5] Edstrom, K. "Academic and Professional Values in Engineering Education - Engaging with History to Explore a Persistent Tension”. Engineering Studies, 2018, 10, 38-65.

[6] Hong-Xin L I, Che Y R. "College Students Integration Diathesis Education in the Concept of CDIO Education Countermeasures". Education Teaching Forum, 2017.9, 163-164. (In Chinese) 